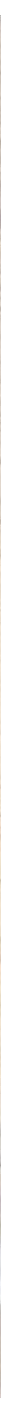

Poblado del Oeste Western-Leone, en el desierto de Tabernas. Foto: Juan Carlos Callaza, IAPH 


\section{El desierto, la luz y el cine}

Ignacio M. Fernández Mañas, historiador del cine
"Escritura del viento en el desierto"

Octavio Paz

Hace casi sesenta años la idiosincrasia del paisaje de las ramblas de Gérgal y de Tabernas, en la cuenca del río Andarax, cautivó la mirada de los cineastas. Desde entonces, se han venido creando innumerables historias hechas de miradas, sombras y luces en este territorio imponente. La quietud insondable de este abrupto, severo y majestuoso paisaje se armonizó con el ajetreado, turbulento y desconcertante mundo del cine. Sus tres mil horas de insolación anual facilitaban el trabajo de esta industria tan dependiente de la luz. Los amaneceres largos y los atardeceres lentos simplificaban la labor creativa de los directores de fotografía y permitían que los rodajes diariamente se prolongaran más de lo habitual.

Aunque 1951 marca el inicio de la historia de los rodajes en Almería con la película española La llamada de África, de César Fernández Ardavín, no fue hasta el rodaje de Oeil pour oeil en 1956 cuando el desierto de Tabernas se convirtió en escenario cardinal de una producción cinematográfica. El gran decorador español Gil Parrondo asumió las labores de localización: "... quedé totalmente alucinado con el paisaje de Tabernas. Nunca había visto nada tan hermoso. Me parecia imposible que esos parajes se encontrasen en España. Las localizaciones las realicé junto con el director, Cayatte, Rafael Carrillo, que era el director de producción, y otra tercera persona que no recuerdo bien quién era, quizá fuese el operador, Chistian Matras. Luego no pude hacerla porque tenía otro contrato ya firmado en Madrid. Se encargó de la decoración un buen amigo mio, José Algueró" (FERNÁNDEZ MAÑAS, 1997: 35).

Sobre la elección de los paisajes de Almeria, el propio director de la película declaró al fotógrafo almeriense Carlos Pérez Siquier en la revista Afal: "...necesitaba un paisaje desértico, dramático. Había visitado Libano, Siria, Jordania, Egipto... Todo es igual, demasiado monótono... Por fin, en la Oficina Geográfica de Paris, me indicaron la posibilidad de encontrar en el sudeste español -zona casi desconocida incluso para los propios españoles- lo que iba buscando. Vine aqui y quedé profundamente impresionado. Esto es único en el mundo, de una belleza realmente sobrecogedora" (PÉREZ SIQUIER, 1956).

El diseño de producción corrió a cargo de Jacques Colombier y, tal como refería Parrondo, la realización de los decorados recayó en José Algueró, quien iniciaba su amplia relación con este estudio abierto que ha sido y es Almería. En los parajes de Tabernas se montó un poblado árabe y se construyó un funicular en un desfiladero cercano al municipio de Rioja.

Sería a lo largo de la década de los sesenta cuando el balneario de Sierra Alhamilla, el barranco del Infierno, la zona minera de El Chorrillo, el monte Alfaro, las balsicas de Alfaro, Las Salinillas, La Sartenilla, los llanos del Duque, el valle del Búho, la venta Araoz, la venta Cañicas; o las ramblas Benavides, del Cautivo, de Indalecio, Lanújar, Viciana, entre otros parajes, se convertirian en lugares preferentes para todo tipo de producciones cinematográficas, haciendo que Almeria significase dentro de la historia del cine moderno "un género en sí mismo... en cuanto establece una íntima conexión, estética y no anecdótica, entre las películas alli rodadas, independientemente de su idiosincrasia" (AGUILAR, 2001: 331). Estos lugares fueron los emblemas del llamado "Hollywood europeo", como fue denominada Almería en estos años. El género western, fundamentalmente, marcó los jalones de este fulgor cinematográfico en una provincia que, por entonces, era la que menos renta per cápita tenía de España; una provincia deprimida, olvidada, carne de emigración y carente de infraestructuras básicas.

Tierra brutal, coproducción hispano-americana, dirigida por Michael Carreras, abrió en 1961 el largo camino que llevaria a que se rodasen más de doscientos westerns en estos parajes. No en vano, el director español Joaquín Romero Marchent contaba: "Los paisajes que viera en el copión de Tierra brutal en la sala de montaje se adecuaban perfectamente a los que necesitaba para mi próximo film. El sabor de la venganza... Para que las películas se parecieran de verdad a lo que eran los westerns americanos..." (SOLER, 1993). Por ello, rodaría varias veces en estos espacios du- 


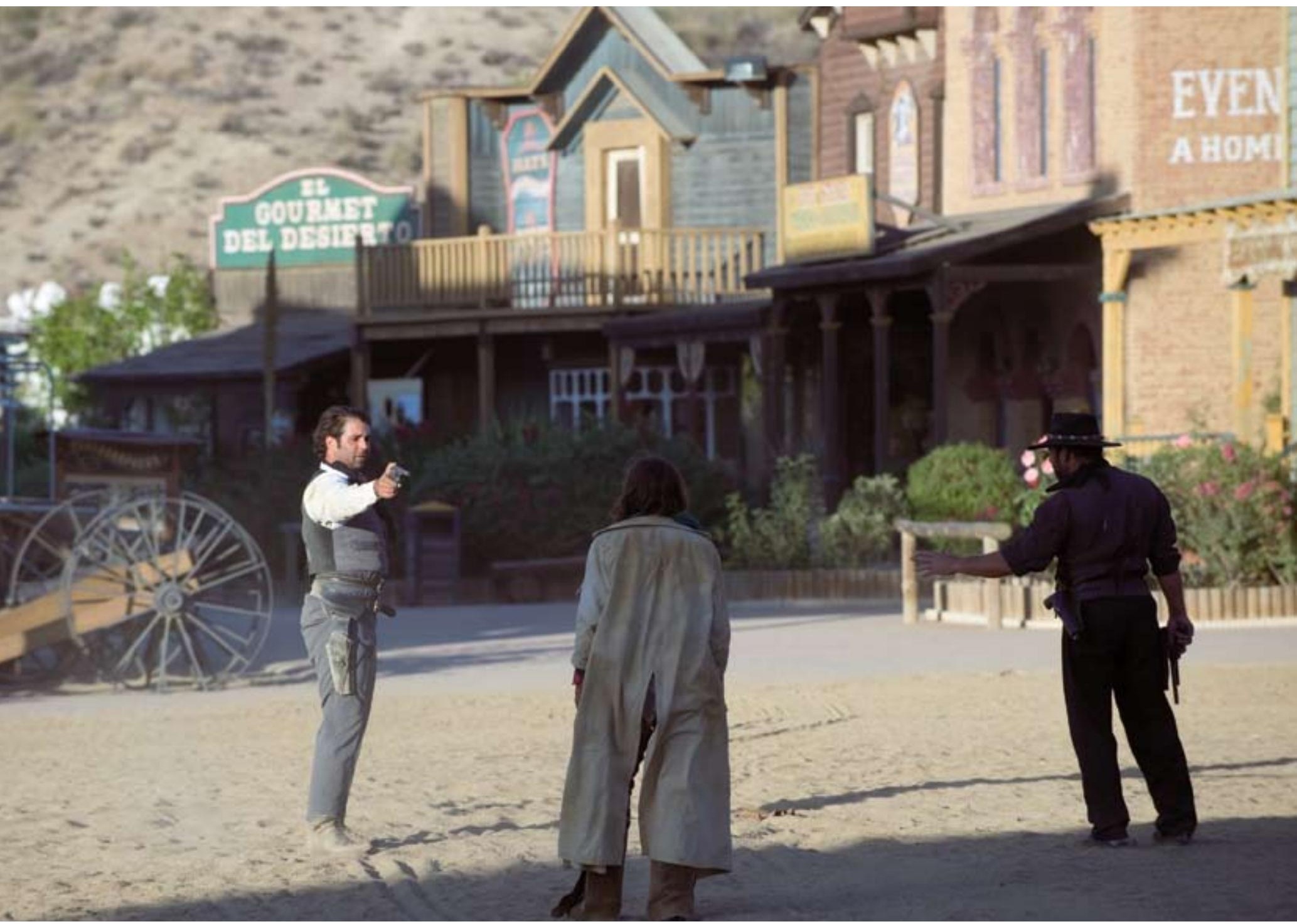

Espectáculo del Oeste en el parque temático Oasys, en el desierto de Tabernas. Foto: Juan Carlos Callaza, IAPH

rante el primer lustro de los sesenta con títulos como Antes llega la muerte -1964- o La muerte cumple condena-1965-.

Sin embargo fue tras el éxito de la película de Sergio Leone Por un puñado de dólares -1964-, cuando la fiebre del western se desató. El Ilamado spaguetti-western hizo que en estas ramblas, en estas áridas, secas, duras y alejadas localizaciones se oyesen voces en castellano, italiano, alemán o inglés. La muerte tenía un precio-1965-, el segundo western de Leone, comenzaba con una vista general de los llanos del Duque sobre los que se sobreimpresionaban los títulos de crédito y se escuchaba la música de Ennio Morricone. Para este film, el director artístico Carlo Simi diseñó el poblado de Fraile', que se levantó en el paraje denominado Cortijo Genaro, dentro del municipio de Tabernas. Su constructor fue Miguel Montoro y los decoradores Carlo Leva y Rafael Ferri. La superficie ocupaba aproximadamente unos cuarenta mil metros cuadrados. Lógicamente, una parte importante de la película transcurría en este poblado, que recreaba la ciudad de El Paso, y en el que se edificaron la oficina del sheriff, la cárcel, el salónhotel y el banco. Otras localizaciones para esta película mítica del western mediterráneo, dentro de la cuenca del Andarax, fueron las balsicas de Alfaro y las ramblas de Indalecio y Viciana, que se aprovecharon para las galopadas de la banda de Indio (personaje interpretado por Gian María Volonté). En 1966, Leone culminó su trilogía del dólar con El bueno, el feo y el malo. De nuevo se utilizó "El poblado de Fraile" para caracterizar tres ciudades distintas; y además la Sartenilla para instalar el poblado fantasma del prólogo, en el que Tuco (Eli Wallach) mata a tres pistoleros; los Llanos del Duque para plasmar el lugar en el que el Rubio (Clint Eastwood) abandona a Tuco desmontado y con las manos atadas; la rambla Lanújar, por donde marchan Tuco y el Rubio, intentando el primero evitar descubrirle el lugar exacto del cementerio de guerra; o el acceso al Colativí, al que ya había recurrido Leone en su anterior western.

Con el aumento de producciones de este género, en otras zonas de la cuenca de las ramblas de Gérgal y Tabernas del Río Andarax se construyeron otros poblados, algunos de ellos todavía en pie (poblado de Juan Garcia ${ }^{2}$ o el rancho Leone ${ }^{3}$ ) y otros, lamentablemente, en ruinas o desaparecidos (la fortaleza construida para la película $E$ I Cóndor-John Guillermin, 1970-; el poblado de Tecisa; el rancho de las Salinillas; el poblado Mimbrero; el fuerte Gobi; etc.). 


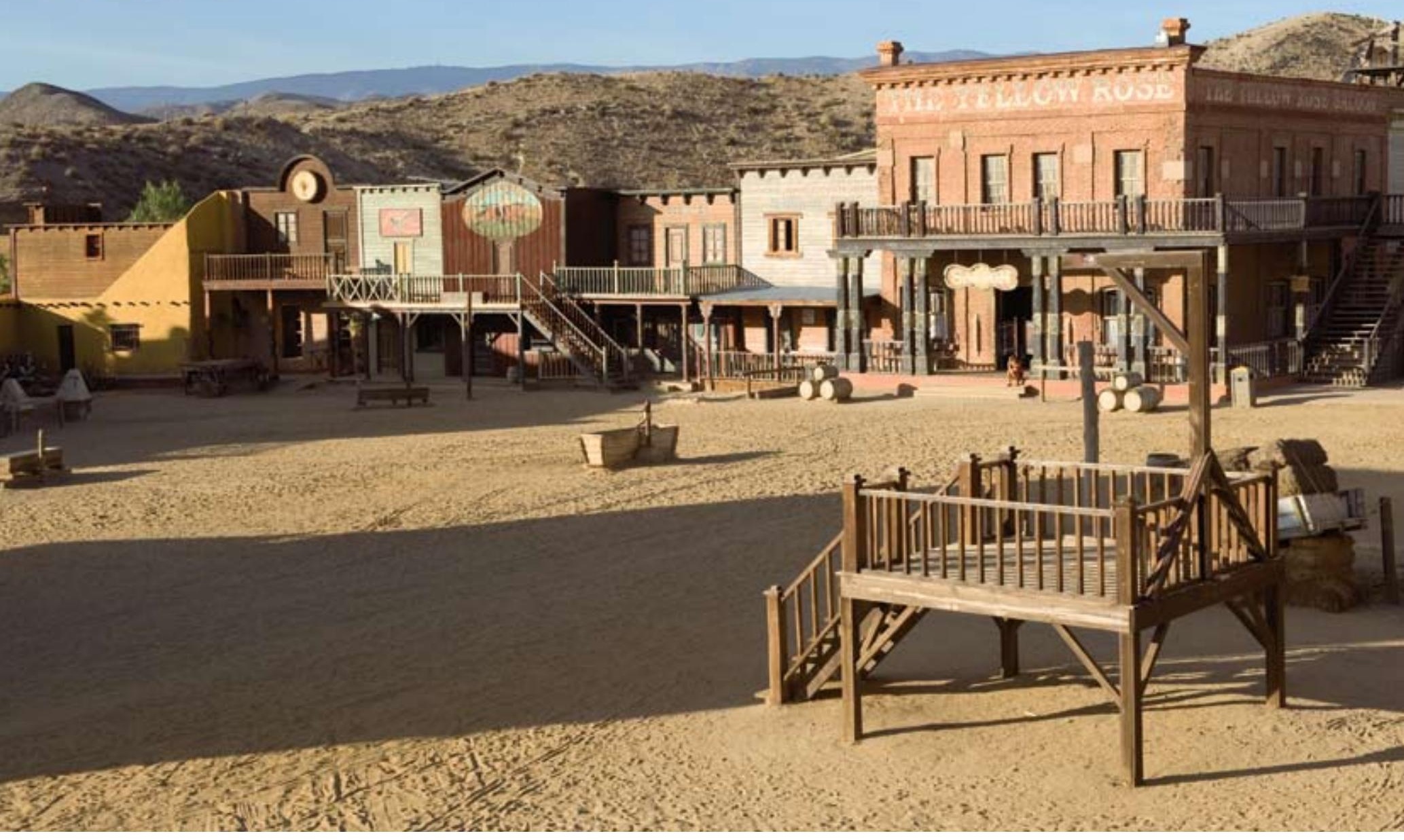

Poblado del Oeste Minihollywood en el parque temático Oasys. Foto: Juan Carlos Callaza, IAPH

Este auge de coproducciones inspiradas en el mundo del western americano entre 1965 y 1975 provocó que estas tierras fueron tomadas por las huestes cinematográficas, creando la ilusión de estar en los predios de Arizona, de Texas, de California o en la zona fronteriza mexicana, por las que cabalgaban y disparaban interpretando historias de robos de trenes, revolución mexicana o cazadores de recompensas intérpretes como los anteriormente mencionados o Brigitte Bardot, Ernest Borgnine, Charles Bronson, Yul Brynner, Claudia Cardinale, James Coburn, Sean Connery, Alain Delon, Henry Fonda, Giuliano Gemma, Terence Hill, Burt Lancaster, Lee Marvin, Francisco Rabal, Burt Reynolds, Bud Spencer, Fernando Rey, Lee Van Cleef, Raquel Welch, Orson Welles y tantos otros. De este modo, estos paisajes consagraron a Almería como la localización "del cinema western piü importante dopo le principali location del West americano" (GABERSCEK, 2005: 2).

Pero no sólo de western se alimentaron estas tierras durante este periodo de apogeo de la industria cinematográfica, otros géneros también contaron con sus escarpados y alucinantes paisajes para crear otro tipo de historias fílmicas. Para Lawrence de Arabia
-1962- de David Lean, con Omar Sharif, Peter O'Toole y Anthony Quinn, hito en el género histórico y bélico, el escenógrafo John Box creó ex profeso un oasis en la rambla Viciana para algunas de sus escenas y luego serviria como escenario para otras muchas películas. En Cleopatra -1963- de Joseph L. Manckiewicz, el diseñador de producción John DeCuir recreó la batalla de Farsalia, con la que comenzaba la película al finalizar los títulos de crédito, en la rambla del Cautivo, contando con la interpretación de Rex Harrison en el papel de Julio César. Años después, en 1966, John Lennon bajo la dirección de Richard Lester trabajó para la antibelicista Cómo gané la guerra en la misma rambla. Para Mercenarios sin gloria, André de Toth dirigió en 1968 a Michael Caine en las ramblas de Tabernas y Rioja. Gil Parrondo consiguió el Oscar en 1971 a la mejor dirección artística por su trabajo en la película bélica Patton -1969- de Franklin J. Schaffner, recreando en el valle del Búho la batalla de El Guettar, u otros momentos de las hazañas de este general en la Segunda Guerra Mundial en otros lugares de la provincia, como en la carretera de Canjáyar, en los términos de Enix y Felix, etc. La cuenca del Andarax sirvió para escenificar en este tipo de películas acciones en el norte de África o en distintas partes de Arabia. 


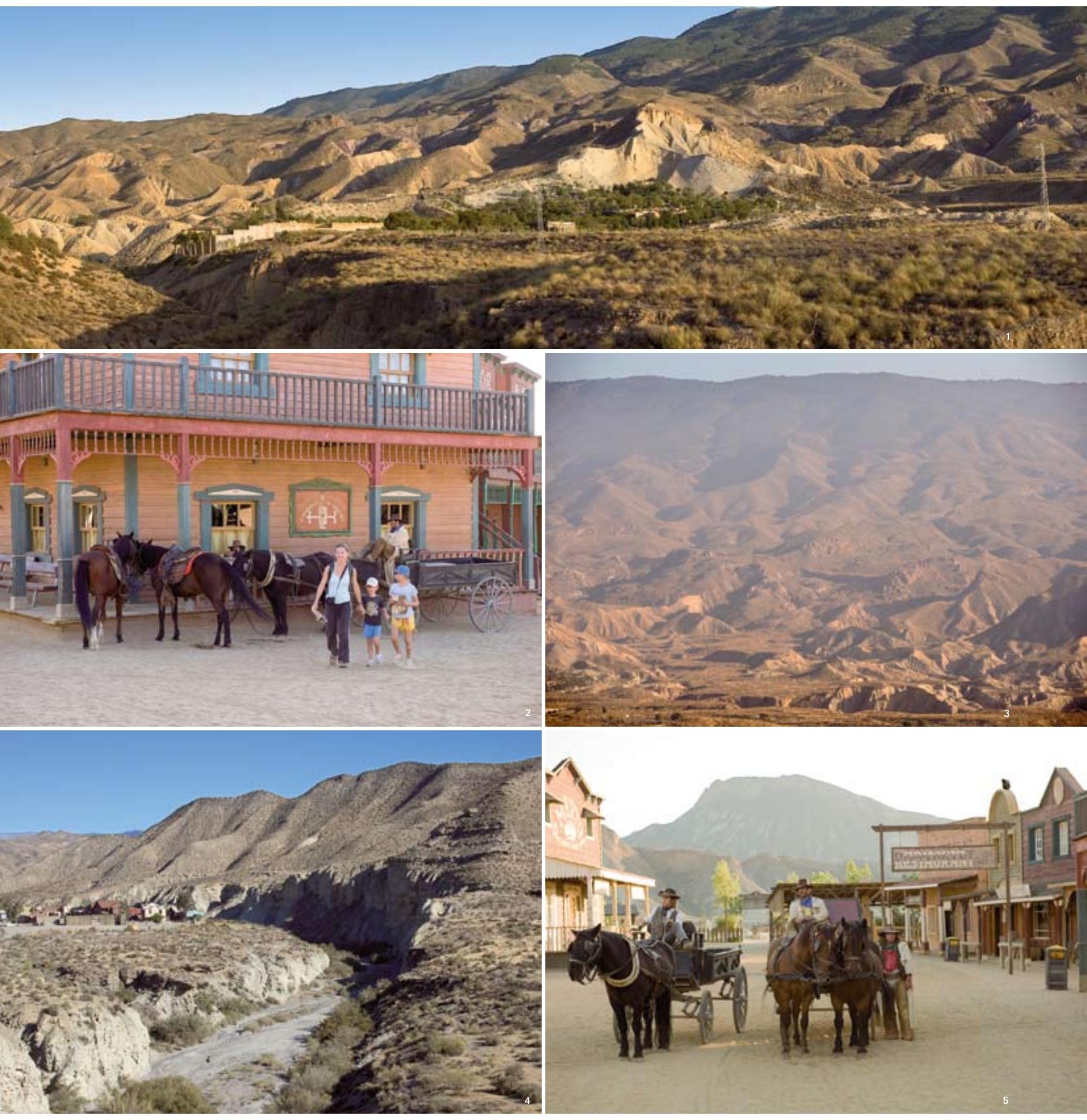

1.Vista del desierto de Tabernas, donde está situado el parque temático Oasys con el poblado del Oeste Minihollywood.

2. Turistas en Minihollywood.

3. Desierto de Tabernas.

4. Poblado del Oeste Western-Leone.

5. Espectáculo del Oeste en Minihollywood.

Fotos: Juan Carlos Callaza, IAPH 
Pero en 1975 se constata que la crisis se ha adueñado del Hollywood europeo. Los factores económicos, políticos y estéticos que se aunaron para levantar esta etapa de grandeza cinematográfica desaparecieron: la cancelación de las medidas legales de apoyo a las coproducciones, el agotamiento del western europeo, la reducción de las películas bélicas sobre la Segunda Guerra Mundial, la crisis del petróleo... Del mismo modo que se fue deshaciendo todo este entramado, los decorados levantados se desmoronaron, arrastrados por el viento, quemados por el sol y olvidados por el cine. El viento y el león -1975- de John Milius acaso marque por sus características el final de la época dorada del cine en Almería. De nuevo Gil Parrondo, como director artístico, transforma la Almería de 1974 y nos ofrece un seductor trabajo de decoración recreando Tánger en el año 1904, así como los desérticos parajes de Gérgal en donde el jeque árabe Mulay Hamid El Raisuli (Sean Connery) tenía sus campamentos. En 1976, todavía la producción británica Valentino -1977-, particular visión biográfica de Rodolfo Valentino dirigida por Ken Rusell, propició el hecho de que en "El poblado de Fraile" se rememorase visualmente el rodaje de un western en los estudios de Hollywood, gracias al trabajo del director de arte Philip Harrison.

De todos modos, no quedó ninguna infraestructura, ningún estudio que pudiera frenar esta decadencia y pudiera resolver el trabajo de especialistas, de caballistas, de localizadores, de transportistas, de carpinteros, de albañiles, que habian encontrado en esta industria una forma de vivir en una de las provincias más deprimidas de España. Fracasaron las medidas de apoyo de los planes de desarrollo de la etapa tecnócrata del franquismo. Sólo los parajes permanecian. Y otras historias y otras formas audiovisuales encontraron acomodo en ellos. No fue con la intensidad de antes, pues no se puede olvidar que el western supuso el setenta por ciento de las producciones en la década dorada. Las producciones para la televisión fueron un componente crucial a partir de los ochenta: capítulos de series de televisión, anuncios publicitarios y los videoclips.

De los dos formatos primeros ya en las dos décadas anteriores se habian grabado episodios para series y anuncios: capítulos para la serie norteamericana The Rat Patrol-1966-, películas para la televisión alemana como Maximiliano Von México -1969-, varios capítulos de la serie española Curro Jiménez -1975 y 1977- o anuncios de cerveza y de alimentación. En las dos últimas décadas del siglo XX, la cuenca del Andarax volvió a ser escenario para capitulos de series bélicas sobre la guerra de Irak (Domsday Gun -1993-), de aventuras (El joven Indiana Jones -1991- o Aventura Eureka-1992-), policiacas (Poirot-1993-), del Oeste (La reina de espadas -2000-) o anuncios de automóviles, de todo tipo de bebidas, de grupos petroquímicos, de golosinas, de tabaco, de cosméticos, inspirados en los westerns rodados en las ramblas y los poblados de antaño y dirigidos la mayoría de las veces a televisiones extranjeras. Y además, un nuevo producto, el videoclip de grupos musicales, halló en estas tierras ya de cine el referente idóneo para ambientar las letras de las canciones o el estilo de los cantantes o grupos: Joaquín Sabina, Sting, Europe, Queen, La Frontera, Siniestro Total, David Bisbal, Tam Tam Go, The Pogues...

Sin embargo, no por ello se dejó de rodar para la pantalla grande. Espectaculares superproducciones se sirvieron de estos paisajes compactos, firmes, perturbadores, indefinibles. Indiana Jones y la útlima cruzada fue la que más impacto tuvo. En 1988 Steven Spielberg con Harrison Ford y Sean Connery filmó secuencias en las ramblas Indalecio y Trujillo. También el cine español se fijó en estos paisajes. Ya lo hizo en los sesenta con westerns en la línea estilística de los italianos, pero ahora en los últimos años del siglo XX y en los primeros del XXI, Mario Camus con José Coronado y Ana Duato en La vuelta de El Coyote -1998- o Alex de la Iglesia con Sancho Gracia y Carmen Maura en 800 balas -2002- volvieron, desde perspectivas diferentes, a emplazar historias filmicas en los ámbitos de la cuenca del Andarax. E incluso la joven cineasta inglesa Linne Ramsay integró la vida cotidiana y tradicional de Ohanes en su película Morvern Callang -2002-. El mundo del cortometraje español, auspiciado por el Festival Internacional de Cortometraje Almeria en corto, desde 2003 ha encontrado también en estas zonas los rincones para aportar nuevas miradas.

El cine a esta cuenca del Andarax le ha dado resonancia mundial. El cine mostró las incalculables posibilidades para que la imaginación audiovisual pudiera crear fantasias e historias que nos conmuevan ante una pantalla. El cine descubrió que en este paisaje están todos los siglos, todos los tiempos, que en el silencio polvoriento de sus ramblas había emoción. El cine halló la forma de sacar prosperidad de su sequedad y dureza, hizo fecundo este desierto, le ofreció la posibilidad de que miles de almerienses pudieran encontrar en los trabajos de la industria cinematográfica un modo para sobrevivir en una época paupérrima para esta provincia como fue la del franquismo. El cine sigue siendo un modo viable de seguir generando trabajo e imaginación. Esta cuenca árida, abrasadora, todavía puede seguir poblándose por unas horas, por unos días o por unas semanas con la gente del cine, todavía su filón no se ha agotado y puede ofrecer nuevas e imaginativas historias, dejando una escritura, una huella intangible como la del viento en el desierto.

\footnotetext{
Notas

${ }^{1}$ Posteriormente se conocería como el poblado Minihollywood. Se denominó "El poblado de Fraile" debido a que Alfredo Fraile era el socio mayoritario de Arturo González y productor ejecutivo de la película por parte española.

${ }^{2}$ Conocido actualmente como el poblado Fort Bravo (antes Texas Hollywood).

${ }^{3}$ Proyectado por el director artístico italiano Carlo Simi para el rodaje de Hasta que Ilegó su hora (1968), de Sergio Leone.
} 